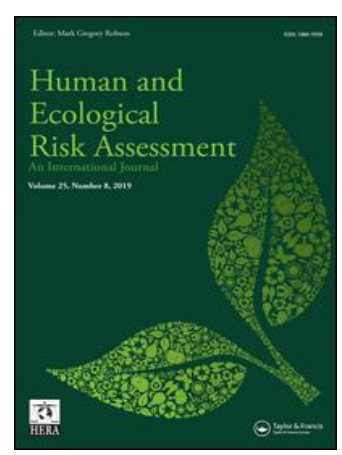

Human and Ecological Risk Assessment: An International Journal

\title{
Pollution, sources, and risks of heavy metals in coastal waters of China
}

Jun Wu, Jian Lu, Cui Zhang, Yuxuan Zhang, Yichen Lin \& Juan Xu

To cite this article: Jun Wu, Jian Lu, Cui Zhang, Yuxuan Zhang, Yichen Lin \& Juan Xu (2019):

Pollution, sources, and risks of heavy metals in coastal waters of China, Human and Ecological

Risk Assessment: An International Journal, DOI: 10.1080/10807039.2019.1634466

To link to this article: https://doi.org/10.1080/10807039.2019.1634466

曲 Published online: 02 Jul 2019.

Submit your article to this journal $\sqsubset$

Џll Article views: 110

Q View related articles $\asymp$

View Crossmark data $₫$ 


\title{
Pollution, sources, and risks of heavy metals in coastal waters of China
}

\author{
Jun $\mathrm{Wu}^{\mathrm{a}}$, Jian Lu ${ }^{\mathrm{b}, \mathrm{c}}$, Cui Zhang ${ }^{\mathrm{b}}$, Yuxuan Zhang ${ }^{\mathrm{b}}$, Yichen $\operatorname{Lin}^{\mathrm{b}}$, and Juan $\mathrm{Xu}^{\mathrm{d}}$ \\ ${ }^{a}$ School of Resources and Environmental Engineering, Ludong University, Yantai, Shandong, People's

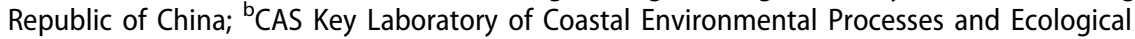 \\ Remediation, Yantai Institute of Coastal Zone Research (YIC), Chinese Academy of Sciences (CAS); \\ Shandong Key Laboratory of Coastal Environmental Processes, YICCAS, Yantai, Shandong, People's \\ Republic of China; 'Center for Ocean Mega-Science, Chinese Academy of Sciences, Qingdao, People's \\ Republic of China; ${ }^{d}$ State Key Laboratory of Marine Geology, Tongji University, Shanghai, People's \\ Republic of China
}

\begin{abstract}
Comprehensive information on heavy metals in coastal waters at national scale of China is limited. Therefore, this study investigated the distribution, pollution, and ecological-health risks of heavy metals in coastal waters along $18,000 \mathrm{~km}$ coastline of China. Total 13 target heavy metals in coastal waters along coastline of China showed drastic spatial variations with average concentrations ranging from $.14(\mathrm{Cd})$ to $136.26(\mathrm{Cu}) \mu \mathrm{g} / \mathrm{L}$. Cu was the dominant heavy metal with the maximal concentration of $1485.92 \mu \mathrm{g} / \mathrm{L}$. Three methods including heavy metal pollution index (HPl), Nemerow index (NI), and contamination degree $(C D)$ were adopted to explore heavy metal pollution. $\mathrm{HPI}$ obtained the worst-case evaluation results to illustrate that heavy pollution occurred at over $50 \%$ of sampling sites. Anthropogenic sources were the main sources of heavy metals in the coastal waters. Approximately $28.13 \%$ and $9.38 \%$ of sampling sites illustrated considerable and very high ecological risks, respectively. Metals including $\mathrm{Cu}, \mathrm{As}$, and $\mathrm{Hg}$ were the main pollution and risk contributors. Heavy metals in coastal waters posed high cancer risks and unacceptable non-cancer risks to both adults and children. Therefore, effective control of heavy metals is necessary for regional sustainability and well-beings of residents in coastal regions of China.
\end{abstract}

\section{ARTICLE HISTORY}

Received 12 May 2019

Revised manuscript accepted 17 June 2019

\section{KEYWORDS}

heavy metal; coastal regions; ecological risks; health risks; source apportionment

\section{Introduction}

Coastal regions, possessing several geomorphological features accompanying with specific dynamics (Carapuço et al. 2016), play critical functions for human society and ecosystems (Lewison et al. 2016). Approximately 40\% of global population lived in coastal regions in 2005 (Agardy and Alder 2005), and same in China until now (Meng et al. 2017). Covering 13\% of the total landmass in China (Meng et al. 2017), coastal regions are disturbed by extensive anthropogenic activities in China. Therefore, pollution

CONTACT Jian Lu $\otimes$ jlu@yic.ac.cn @ CAS Key Laboratory of Coastal Environmental Processes and Ecological Remediation, Yantai Institute of Coastal Zone Research (YIC), Chinese Academy of Sciences (CAS); Shandong Key Laboratory of Coastal Environmental Processes, YICCAS, Yantai Shandong 264003, P. R. China.

Color versions of one or more of the figures in the article can be found online at www.tandfonline.com/bher.

(C) 2019 Taylor \& Francis Group, LLC 
including heavy metal pollution in these regions has been frequently reported (Feng et al. 2011; Wang et al. 2013; Xu et al. 2017).

Heavy metals, referred to metals or metalloids with a density larger than $5 \mathrm{~g} / \mathrm{cm}^{3}$ (Oves et al. 2012), have attracted global attention due to inherent toxicity, nondegradability, persistence, and frequent detection in different matrices (Ranjbar Jafarabadi et al. 2017; Toro et al. 2016; Wang et al. 2013; Zhang et al. 2017). Heavy metals in coastal water significantly affect water quality and aquatic ecosystem if their concentrations exceed certain thresholds (Tueros et al. 2008). Moreover, heavy metals in aquatic system directly or indirectly play critical role in human health owing to their bioaccumulation and biomagnifications through food chain and carcinogenic effects (Zhang et al. 2017). Therefore, it is of urgent importance to discuss issues on heavy metals in coastal waters.

China has one of the longest coastlines in the world and stretches from Liaoning $\left(53^{\circ} 30^{\prime} \mathrm{N}\right)$ in the north to Guangxi $\left(18^{\circ} 15^{\prime} \mathrm{N}\right)$ in the south (Degger et al. 2016). Although, pollution in some local coastal regions of China including Bohai Bay, Laizhou Bay, and South China has become research hotspot (Feng et al. 2011; Wang et al. 2013; Xu et al. 2017), comprehensive information on pollution in large-scale region is still limited because most of research focused on local/small-scope areas. It is necessary to obtain comprehensive and thorough information on heavy metal pollution in coastal waters along Chinese coastline to provide basis for making environmental protection policies.

Therefore, this study collected coastal water samples to analyze the concentrations of typical heavy metals along typical coastline of China. The objectives of this study are to determine the distribution of heavy metals in coastal water and discuss the potential ecological-health risks posed by heavy metals in coastal waters. The final aim of this study is to address research basis for sustainable development in coastal regions of China and other countries.

\section{Materials and methods}

\section{Study area, sampling, and analysis}

Field sampling was carried out during November of 2017. Coastal water samples were collected from four representative coastal regions in China including Yellow Sea Area (Y1-Y11), Bohai Area (B1-B8), East China Sea Area (E1-E6), and South China Sea Area (S1-S7; Figure 1). Sampling locations included different functional zones such as the maricultural zones, bathing beaches, estuaries, and ports.

Surface coastal water samples were collected from $.5 \mathrm{~m}$ below the water surface using $1 \mathrm{~L}$ pre-cleaned amber glass sample bottles. The water samples were filtered using $.45 \mu \mathrm{m}$ membrane filters (Pall Life Sciences, Ann Arbor, MI, USA) before analysis. Water samples were analyzed using an Agilent7900 inductively coupled plasma mass spectrometry (ICP-MS, Agilent Inc, USA). Concentrations of 13 typical heavy metals including antimony (Sb), arsenic (As), cadmium (Cd), chromium (Cr), cobalt (Co), copper $(\mathrm{Cu})$, vanadium $(\mathrm{V})$, lead $(\mathrm{Pb})$, mercury $(\mathrm{Hg})$, molybdenum $(\mathrm{Mo})$, nickel $(\mathrm{Ni})$, tin $(\mathrm{Sn})$, and zinc $(\mathrm{Zn})$ were determined. Method detection limit (MDL) for As/Cd/Cr/Co/ $\mathrm{Cu} / \mathrm{Sb} / \mathrm{V} / \mathrm{Pb} / \mathrm{Hg} / \mathrm{Mo} / \mathrm{Ni} / \mathrm{Sn} / \mathrm{Zn}$ was 164/16/96/12/132/14/29/17/8/29/36/17/336 ng/L. Two purewater samples spiked with standard mixture solution of target heavy metals were 


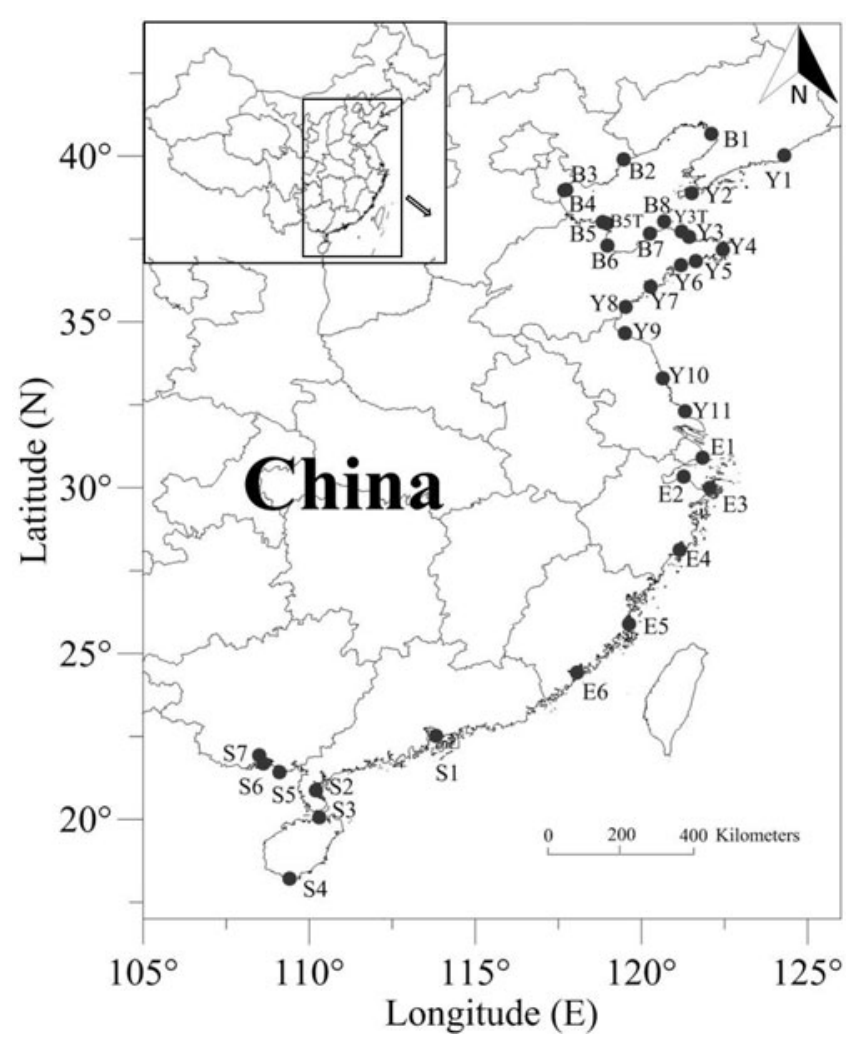

Figure 1. Location of sampling sites.

inserted for analysis series of every 5 real water samples to ensure quality control. The recoveries of target heavy metals ranged from $92.4 \%$ to $114.3 \%$ to indicate that the ICPMS analysis was satisfactory for requirement of data quality.

Salinity of each water sample was determined by a portable refractometer (LH-Y100, Lohand Biological, China). Concentrations of total nitrogen (TN) and total phosphorus (TP) in coastal water samples were analyzed using a continuous flow analyzer (AutoAnalyzer III, Seal, Germany). A total organic carbon analyzer (TOC-VCPH, Shimadu, Japan) was used to measure total organic carbon (TOC).

The comparison on concentrations of heavy metals at different sites was evaluated using analysis of variance (ANOVA) by calculating the least significant differences (LSD, $p=.01)$.

\section{Correlation analysis and positive matrix factorization model}

Pearson correlation coefficients were employed to determine the relationship between water quality parameters and heavy metals. Correlation analysis was performed using SPSS 19.0 (IBM, NY, USA).

Positive matrix factorization (PMF) was used to determine the possible sources of heavy metals in coastal waters. The detailed information on PMF was provided by USEPA (2014). 


\section{Pollution assessment of heavy metals in coastal waters}

The Nemerow index (NI), heavy metal pollution index (HPI), and contamination degree $(C D)$ were used to evaluate the pollution of heavy metals in coastal waters along Chinese coastline.

NI was calculated according to the following equation (Liu et al. 2015; Vu et al. 2017):

$$
N I=\sqrt{\frac{\left(\frac{C_{i}}{S_{i}}\right)_{\text {mean }}^{2}+\left(\frac{C_{i}}{S_{i}}\right)_{\max }^{2}}{2}}
$$

where $C_{i}$ and $S_{i}$ refer to the measured concentration $(\mu \mathrm{g} / \mathrm{L})$ and assessment standard concentration $(\mu \mathrm{g} / \mathrm{L})$ of the target heavy metal in coastal water; $\left(\frac{C_{i}}{S_{i}}\right)_{\text {mean }}$ and $\left(\frac{C_{i}}{S_{i}}\right)_{\max }$ stand for the average value and maximal value of $\left(\frac{C_{i}}{S_{i}}\right)$ among all target heavy metals. Values of $S_{i}$ used in this study were set as the Class II levels of "Sea water quality standard of China (GB 3097-1997)" which targeted at aquaculture zones, bathing beaches, sporting, or entertainment zones, and industrial water supply zones relating with human consumption. Four pollution categories were given including insignificant pollution (Class I, $N I<1$ ), slight pollution (Class II, $1 \leq N I<2.5$ ), moderate pollution (Class III, $2.5 \leq N I<7$ ), and heavy pollution (Class IV, $N I \geq 7$ ) according to evaluation criterion (Liu et al. 2015; Vu et al. 2017).

HPI model was given by the following equation ( $\mathrm{Qu}$ et al. 2018):

$$
H P I=\frac{\sum_{i=1}^{n}\left(\frac{C_{i}}{S_{i}} \times 100\right) \times\left(\frac{k}{S_{i}}\right)}{\sum_{i=1}^{n} \frac{k}{S_{i}}}
$$

where $k$ is a proportionality constant and set as 1 (Qu et al. 2018) and $n$ represents the numbers of target heavy metals. Comprehensively comparing the current criteria (Edet and Offiong 2002; Qu et al. 2018), this study adopted the following evaluation categories: low pollution (Classes I, $H P I<15$ ), moderate pollution (Class II, $15 \leq H P I \leq 30$ ), moderate-to-heavy pollution (Class III, $30<H P I \leq 100$ ), and heavy pollution (Class IV, $H P I>100)$.

The following equation showed the calculation of CD (Sharifi et al. 2016):

$$
C D=\sum_{i=1}^{n} \frac{C_{i}}{S_{i}}
$$

Sharifi et al. (2016) also provided the evaluation criterion: low pollution (Classes I, $C D<6$ ), moderate pollution (Class II, $6 \leq C D<12$ ), considerable pollution (Class III, $12 \leq C D<24$ ), and very heavy pollution (Class IV, $C D \geq 24$ ).

\section{Ecological risk assessment of heavy metals in coastal waters}

The potential ecological risks posed by heavy metals in coastal waters were evaluated using the following ecological risk index (ERI) model (Sharifi et al. 2016): 


$$
E R I=\sum_{i=1}^{n} T_{i} \times \frac{C_{i}}{S_{i}}
$$

where $T_{i}$ is the potential ecological risk coefficient of a target heavy metal. The values of $T_{i}$ for all target heavy metals were selected from the literatures (Hakanson 1980; Sharifi et al. 2016). Sharifi et al. (2016) listed the ranking criterion for ecological risks: low risk $(E R I<110)$, moderate risk $(110 \leq E R I<200)$, considerable risk $(200 \leq E R I<400)$, and very high risk $(E R I \geq 400)$.

\section{Heath risk assessment of heavy metals in coastal waters}

The health risks were evaluated using cancer risks and hazard quotients by the following equations (USEPA 2004):

$$
\begin{gathered}
C R(\text { individual })=D A D \times \frac{S F_{O}}{G I A B S}=D A_{\text {event }} \times \frac{E V \times E D \times E F \times S A}{B W \times A T} \times \frac{S F_{O}}{G I A B S} \\
=K_{P} \times C_{W} \times t_{\text {event }} \times \frac{E V \times E D \times E F \times S A}{B W \times A T} \times \frac{S F_{O}}{G I A B S} \\
H Q(\text { individual })=D A D \times \frac{1}{R f D_{O} \times G I A B S}=D A_{\text {event }} \\
\times \frac{E V \times E D \times E F \times S A}{B W \times A T} \times \frac{1}{R f D_{O} \times G I A B S} \\
=K_{P} \times C_{W} \times t_{\text {event }} \times \frac{E V \times E D \times E F \times S A}{B W \times A T} \times \frac{1}{R f D_{O} \times G I A B S} \\
C R=\sum C R(\text { individual }) \\
\left.H Q=\sum H Q \text { (individual }\right)
\end{gathered}
$$

where $D A D$ and $D A_{\text {event }}$ are absorbed dose by dermal contact and absorbed dose of each event, respectively; $S F_{O}$ represents oral slope factor; GIABS is the fraction of chemical absorbed in gastrointestinal tract; $R f D_{O}$ refers to oral reference dose; $E V, E D$, and $E F$ represent the event frequency, exposure duration, and exposure frequency, respectively; $S A$ refers to skin surface area; $B W$ means body weight; $A T$ is average lifespan; $K_{P}$ refers to dermal permeability coefficient of pollutant; $C_{W}$ is concentration of pollutant in coastal water; $t_{\text {event }}$ represents event duration. The values of parameters were obtained from the references (Akhbarizadeh et al. 2016; IRIS 2018; Ranjbar Jafarabadi et al. 2017; Sarria-Villa et al. 2016; USEPA 2004, 2016). The values of parameters were listed in Table 1. Based on ranking criterion (Ge et al. 2013), cancer risks were categorized into five levels including very low $\left(C R \leq 1 \times 10^{-6}\right)$, low $\left(1 \times 10^{-6}<C R \leq 1 \times 10^{-4}\right)$, moderate $\left(1 \times 10^{-4}<C R \leq 1 \times 10^{-3}\right)$, high $\left(1 \times 10^{-3}<C R \leq .1\right)$, and very high $(C R>.1)$. Unacceptable threshold of non-cancer risks was set as $1(\mathrm{Qu}$ et al. 2018; Zhang et al. 2017). 


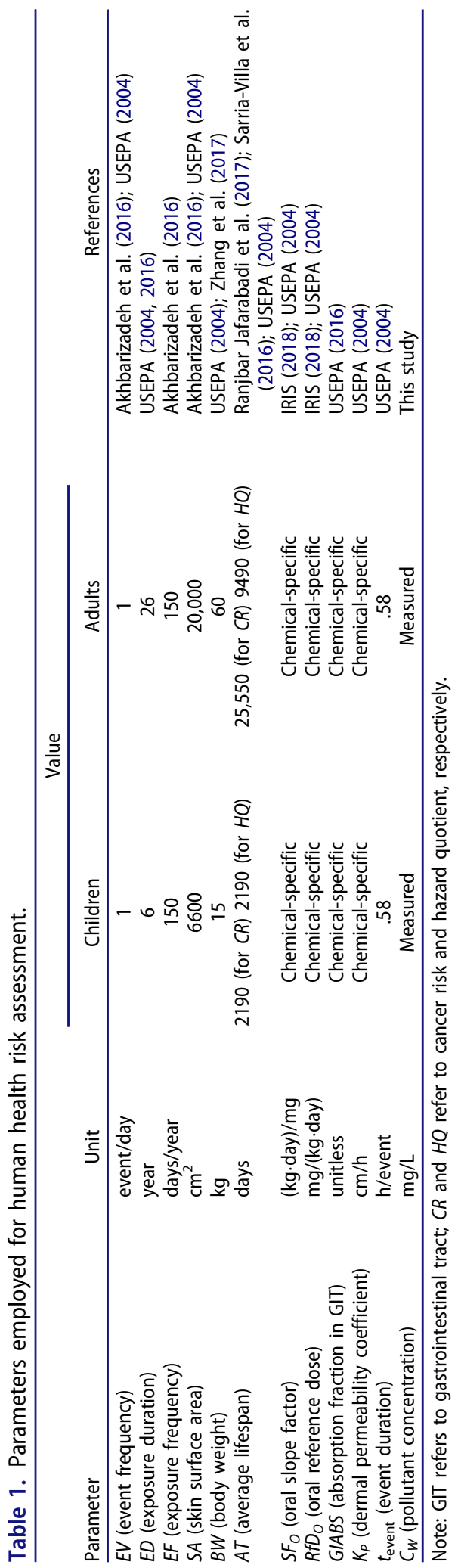




\section{Results and discussion}

\section{Occurrence and distribution of heavy metals in coastal waters}

Statistical summary on concentrations of heavy metals in coastal waters was shown in Table 2. The average concentrations of heavy metals ranged from .14 (Cd) to 136.26 $(\mathrm{Cu}) \mu \mathrm{g} / \mathrm{L}$. Significant differences in concentrations of heavy metals were proved by ANOVA results. $\mathrm{Cu}$ was the dominant heavy metal in coastal waters with the concentrations ranging from 6.24 (at S2) to 1485.92 (at B5) $\mu \mathrm{g} / \mathrm{L}$, illustrating the most significant spatial variation. As surprisingly showed high concentrations varying from 4.20 (at S2) to 112.64 (at B2) $\mu \mathrm{g} / \mathrm{L}$ with the average value of $78.08 \mu \mathrm{g} / \mathrm{L}$. $\mathrm{Zn}$ and V also showed the relatively high average concentrations. The minimal/maximal concentrations of $\mathrm{Zn}$ and $\mathrm{V}$ occurred at $\mathrm{Y} 5 / \mathrm{Y} 3$ and S2/B5, respectively. Concentrations of Mo varied from 1.91 (at S2) to 14.35 (at B5) $\mu \mathrm{g} / \mathrm{L}$, showing the relatively low fluctuation in contrast with $\mathrm{Cu}, \mathrm{Ni}, \mathrm{Zn}, \mathrm{Co}, \mathrm{V}, \mathrm{Cd}, \mathrm{Sn}, \mathrm{Sb}, \mathrm{Hg}$, and $\mathrm{Pb}$. Except E4 and S2 at which $\mathrm{Ni}$ was not detected, concentrations of Ni ranged from 2.48 (Y1) to 46.68 (at B5) $\mu \mathrm{g} / \mathrm{L}$. Except Y4 and $\mathrm{Y} 6$ at which $\mathrm{Pb}$ was not detected, concentrations of $\mathrm{Pb}$ were in the range of .02 (at Y3)-5.67 (at Y5) $\mu \mathrm{g} / \mathrm{L}$. Concentrations of Cr were in the range of 1.36 (at S7)-4.68 (at B5) $\mu \mathrm{g} / \mathrm{L}$, also exhibiting relatively low fluctuation similar to Mo. Concentrations of $\mathrm{Hg}$ ranged from .006 (at E3) to 1.68 (at Y8) $\mu \mathrm{g} / \mathrm{L}$ at sampling sites except Y9, Y10, E5, E6, S1, and S3-S7. The minimal and maximal concentrations of Cd occurred at B5 and E4, respectively. In summary, distribution of heavy metals exhibited drastic spatial variations.

The maximal average concentration of many target heavy metals $(\mathrm{Cr}, \mathrm{Co}, \mathrm{Ni}, \mathrm{Cu}, \mathrm{As}$, $\mathrm{Mo}, \mathrm{Cd}, \mathrm{Sn}, \mathrm{Sb}$ ) in coastal waters occurred in Bohai Area. The maximal average concentration of $\mathrm{V}, \mathrm{Zn}$, and $\mathrm{Hg}$ in coastal waters occurred in Yellow Sea Area while that of $\mathrm{Pb}$ occurred in South China Sea Area. Average concentration of Cr, As, and Mo in coastal waters followed the order of Bohai Area $>$ Yellow Sea Area $>$ East China Sea Area $>$ South China Sea Area while that of $\mathrm{Co}, \mathrm{Ni}$, and $\mathrm{Cu}$ followed the order of Bohai Area $>$ Yellow Sea Area $>$ South China Sea Area $>$ East China Sea Area. Average concentration of $\mathrm{V}$ and $\mathrm{Zn}$ in coastal waters followed the order of Yellow Sea Area $>$ Bohai Area $>$ South China Sea Area $>$ East China Sea Area while that of Cd and Sb followed the order of Bohai Area $>$ East China Sea Area $>$ South China Sea Area $>$ Yellow Sea Area.

Concentrations of several heavy metals including $\mathrm{Cr}, \mathrm{Cd}, \mathrm{Ni}, \mathrm{Zn}$, and $\mathrm{Pb}$ in coastal waters of this study were lower than those in surface water near Yeongil Bay, Korea

Table 2. Statistical summary on salinity, TOC, TN, TP, and heavy metal concentrations in coastal waters ( $\mu \mathrm{g} / \mathrm{L}$ for all heavy metals; \% for salinity; $\mathrm{mg} / \mathrm{L}$ for TOC, TN, and TP).

\begin{tabular}{|c|c|c|c|c|c|c|c|c|c|c|c|c|c|c|c|c|c|}
\hline & V & $\mathrm{Cr}$ & Co & $\mathrm{Ni}$ & $\mathrm{Cu}$ & $\mathrm{Zn}$ & As & Mo & $\mathrm{Cd}$ & $\mathrm{Sn}$ & $\mathrm{Sb}$ & $\mathrm{Hg}$ & $\mathrm{Pb}$ & salinity & TOC & TN & TP \\
\hline 0 & 29.44 & 55 & .92 & 3.59 & 136.26 & 32.42 & 78.08 & 10.09 & .14 & .39 & 1.38 & .56 & 2.08 & 26 & 6.32 & 1.93 & .05 \\
\hline SE & & .14 & .07 & 1 & & , & 2 & .59 & .01 & .06 & .13 & .10 & .26 & 2 & .98 & .15 & .01 \\
\hline $\mathrm{Mec}$ & 25. & 2.27 & .89 & 13.35 & 60. & 27 & 82.59 & 11.16 & .13 & .29 & 1.22 & .44 & 1.76 & Ju & 4.50 & 1.97 & .04 \\
\hline 2 & 4 & 1.36 & .21 & $\mathrm{BDL}$ & 6 & 0 & 4.20 & 1.91 & .02 & .03 & .43 & $\mathrm{BDL}$ & $\mathrm{BDL}$ & 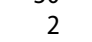 & 2.47 & .56 & .01 \\
\hline Maximum & 59.47 & 4.68 & 1.68 & 46.68 & 1485.92 & 88.40 & 112.64 & 14.35 & .30 & 1.55 & 4.35 & 1.68 & 5.67 & 35 & 29.42 & 3.87 & .17 \\
\hline
\end{tabular}

Note: TOC, TN, and TP refer to total organic carbon, total nitrogen, and total phosphorus; SE means standard error; BDL means below the detection limit. 
(Kim et al. 2014). Concentrations of Cd and Co in coastal waters of China (this study) were lower than those in Sagami River and Bay of Japan (Takata et al. 2012). Concentrations of $\mathrm{Cd}, \mathrm{Cr}, \mathrm{Ni}$, and $\mathrm{Pb}$ in coastal waters of SW Gulf of California coast were higher than those of this study (Jonathan et al. 2017) while concentrations of $\mathrm{Pb}$ and Cd in coastal waters of this study were comparable with those in coastal regions of South-Western Sardinia, Italy (Cherchi et al. 2009).

\section{Heavy metal pollution along Chinese coastline}

Pollution of individual heavy metals including $\mathrm{Cr}, \mathrm{Ni}, \mathrm{Cu}, \mathrm{Zn}$, As, $\mathrm{Cd}, \mathrm{Hg}$, and $\mathrm{Pb}$ was evaluated by comparing corresponding Class II standards of "Sea water quality standard of China (GB 3097-1997)" which only listed these metals. Concentrations of $\mathrm{Cd}$ and $\mathrm{Cr}$ in coastal waters were much less than Class II levels of $5(\mathrm{Cd})$ and 100 (Cr) $\mu \mathrm{g} / \mathrm{L}$, respectively. Concentrations of $\mathrm{Pb}$ at $\mathrm{B} 5$ and $\mathrm{S} 1$ exceeded its standard $(5 \mu \mathrm{g} / \mathrm{L})$ while those at the remaining sites were less than quality standard. Concentrations of $\mathrm{Zn}$ at 3 sites (B5, Y3, and S1) exceeded its standard (50 $\mu \mathrm{g} / \mathrm{L}$ ) while those at the remaining sites were less than quality standard. $\mathrm{Cu}$ and $\mathrm{As}$ showed significant pollution since concentrations of them at 30 sites exceeded Class II standards. Concentrations of $\mathrm{Ni}$ at 25 sites exceeded its standard $(10 \mu \mathrm{g} / \mathrm{L})$ while those of $\mathrm{Hg}$ at 16 sites exceeded the Class II standard $(.2 \mu \mathrm{g} / \mathrm{L})$. Heavy metals including $\mathrm{Cu}$, As, $\mathrm{Ni}, \mathrm{Hg}, \mathrm{Zn}$, and $\mathrm{Pb}$ generally caused pollution in coastal waters to different extents.

Three methods were used to evaluate the comprehensive pollution caused by $\mathrm{Cr}$, $\mathrm{Ni}, \mathrm{Cu}, \mathrm{Zn}, \mathrm{As}, \mathrm{Cd}, \mathrm{Hg}$, and $\mathrm{Pb}$ since only these 8 metals possessed assessment standard concentrations (Figure 2). NI values ranged from 1.91 (at S2) to 106.00 (at B5). Based on NI ranking criterion, total 6, 14, and 12 out of 32 sampling sites exhibited slight, moderate, and heavy pollution, respectively. NI used average and maximal values of $\frac{C_{i}}{S_{i}}$ for evaluation so that heavy metals possessing the highest $\frac{C_{i}}{S_{i}}$ value would become the dominant pollution contributor. Metalloid As served as the predominant contributor of pollution at sampling sites Y1, Y10, E1, E2, E3, and S7. $\mathrm{Hg}$ was the main contributor of pollution at sampling sites of $\mathrm{B} 1, \mathrm{E} 4$, and $\mathrm{S} 2$. $\mathrm{Cu}$ served as the predominant contributor of pollution at the remaining sites, followed by $\mathrm{As}$ and $\mathrm{Hg}$.

HPI values of sampling sites varied from 7.39 (at Y10) to 787.98 (at Y8). Approximately $25 \%, 18.75 \%, 3.13 \%$, and $53.13 \%$ of sampling sites showed low, moderate, moderate-to-heavy, and heavy pollution, respectively. $\mathrm{Cu}$ served as the predominant pollution contributor of 13 sampling sites (B5, B7, Y9, Y10, E3, E5, E6, S3, S4, S5, S6, and S7) while $\mathrm{Hg}$ was the main pollution contributor for the rest of sampling sites. Heavy metal pollution assessed by HPI was more serious than that evaluated by NI.

$C D$ values ranged from 4.8 (at S2) to 158.78 (at B5). Based on $C D$ ranking criterion, approximately $2,15,5$, and 10 out of 32 sampling sites illustrated low, moderate, considerable (heavy), and very heavy pollution, respectively. $\mathrm{Cu}$ was the main pollution contributor for most of sampling sites. Heavy metal pollution assessed by $C D$ was also more serious than that evaluated by NI. 

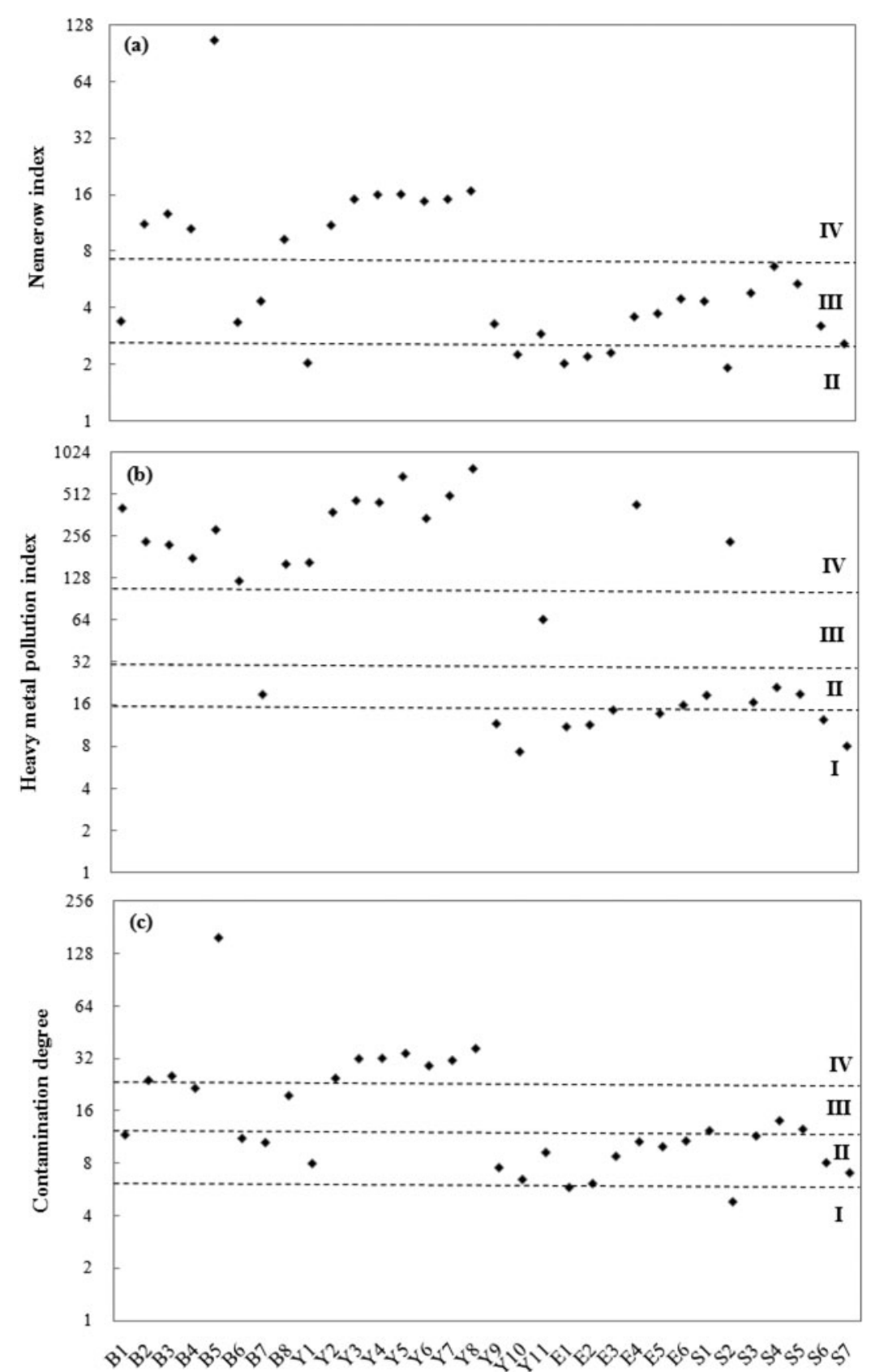

Figure 2. Heavy metal pollution of coastal waters using different evaluation methods. Classes II, III, and IV of Nemerow index represent slight, moderate, and heavy pollution, respectively; Classes I, II, III, and IV of heavy metal pollution index refer to low, moderate, moderate-to-high, and heavy pollution, respectively; Classes I, II, III, and IV of contamination degree stand for low, moderate, considerable, and very heavy pollution, respectively.

In general, Yellow Sea Area and Bohai Area showed more serious heavy metal pollution than East China Sea Area and South China Sea Area. The most serious heavy metal pollution occurred in the region near B5. Northern 
Chinese coastline needs urgent and effective heavy metal pollution control and management.

\section{Possible sources of heavy metals in coastal waters}

Pearson correlation coefficients were used to analyze the potential relationship among heavy metals and water quality parameters (Table 3). Significantly positive relationship existed between every two metals of $\mathrm{V}, \mathrm{Cr}, \mathrm{Co}, \mathrm{Ni}, \mathrm{Cu}$, and $\mathrm{Mo}$, indicating that these metals might originate from the same source. Sn was significantly related with $\mathrm{V}$ and $\mathrm{Sb}$ at $p<.01$ while $\mathrm{Pb}$ was significantly related with $\mathrm{Hg}$ and $\mathrm{Sb}$ at $p<.01$. $\mathrm{Cu}$ was positively related with $\mathrm{Zn}$ and negatively related with $\mathrm{Cd}$ at $p<.05$ while $\mathrm{Hg}$ was also related with $\mathrm{Cr}$, Co, and $\mathrm{Sn}$ at $p<.05$. Salinity was significantly related with $\mathrm{V}, \mathrm{Cr}, \mathrm{Co}, \mathrm{Ni}, \mathrm{Mo}$, and $\mathrm{Sn}$ while TOC was significantly related with Co, $\mathrm{Mo}, \mathrm{Sn}, \mathrm{Sb}$, and $\mathrm{Pb}$. TN was significantly related with $\mathrm{As}, \mathrm{Sn}$, and $\mathrm{Hg}$ while TP was significantly negatively related with $\mathrm{Hg}$. Complex relationship between heavy metals illustrated that multiple sources might affect the distribution of heavy metals in coastal waters.

Three possible sources were determined based on PMF analysis (Figure 3). Metals including V, Co, Ni, Cu, As, Mo, and Cd were mainly controlled by Factor 3 that might originate from discharge of industrial wastewater and sewage, agricultural runoff, and mining inputs. $\mathrm{Pb}, \mathrm{Zn}$, and $\mathrm{Sn}$ were mainly from industrial wastewater and traffic source (Factor 2) since these three metals frequently occurred in industrial wastewater and $\mathrm{Pb}$ were also an important component of fuel. $\mathrm{Hg}$ was mainly controlled by Factor 1 that might be from combustion of fossil fuels and reverine inputs. Heavy metals in coastal waters often concurrently originated from three possible sources, suggesting the source complexity and challenge of effective pollution control. Three possible sources were mainly triggered by the anthropogenic activities, illustrating that rational industry planning is critical for sustainability of the coastal regions.

\section{Potential ecological risks of heavy metals in coastal waters}

Potential ecological risks of heavy metals were evaluated using ecological risk index based on ranking criterion (Figure 4). Approximately 15, 5, 9, and 3 out of 32 sampling sites illustrated low, moderate, considerable, and very high risk, respectively. $\mathrm{Cu}, \mathrm{Hg}$, and As accounted for most of the ecological risks, serving as the dominant risk contributors for 14, 13, and 5 sampling sites, respectively. Sites B5, Y5, and Y8 exhibited very high ecological risks, which corresponded with very high heavy metal pollution at the same site. Ecological risks of heavy metals in $64 \%$ of sampling sites in Yellow Sea Area were considerable or very high, more serious than those in the other areas. Accordingly, approximately $50 \%$ of sampling sites in Bohai Area showed considerable or very high ecological risks. South China Sea Area showed low (86\%) or moderate (14\%) ecological risks of heavy metals, exhibiting the lowest risks among 4 sampling areas. Ecological risks increased with more strict assessment standard concentrations $\left(S_{i}\right)$. Approximately $6,7,4$, and 15 sites showed low, moderate, considerable, and very high risk, respectively when Class I standards of "Sea water quality standard of China (GB 3097-1997)" were 


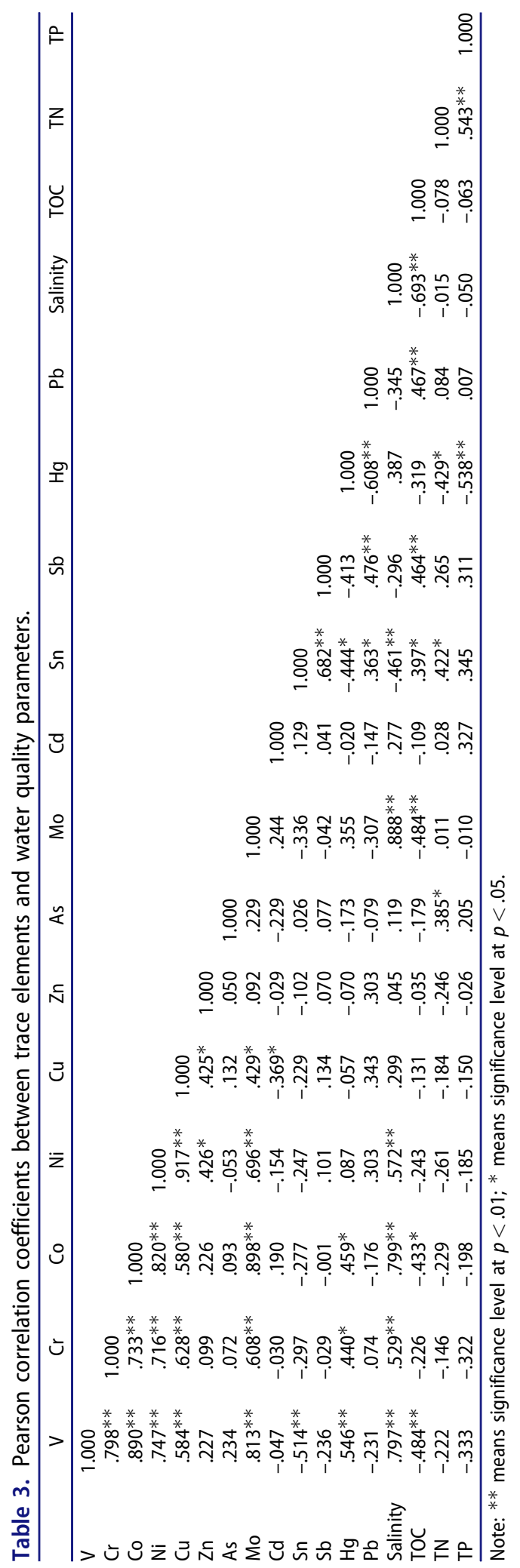




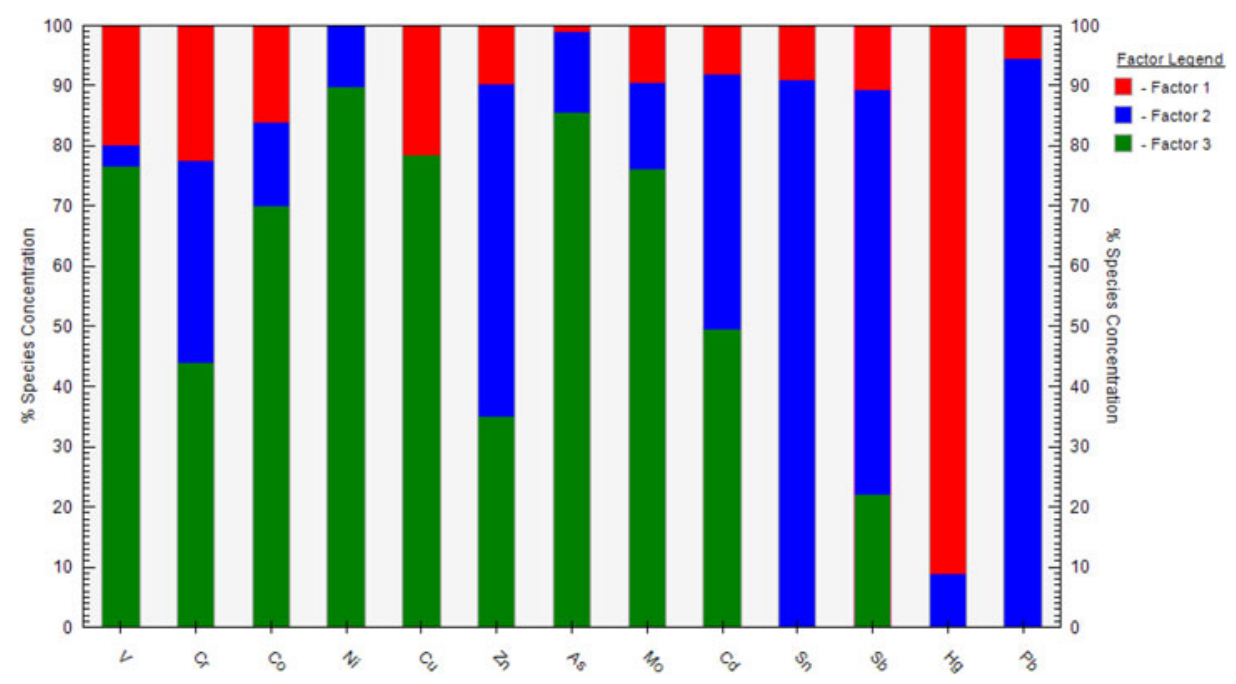

Figure 3. Factor fingerprints of heavy metals in coastal waters along Chinese coastline.

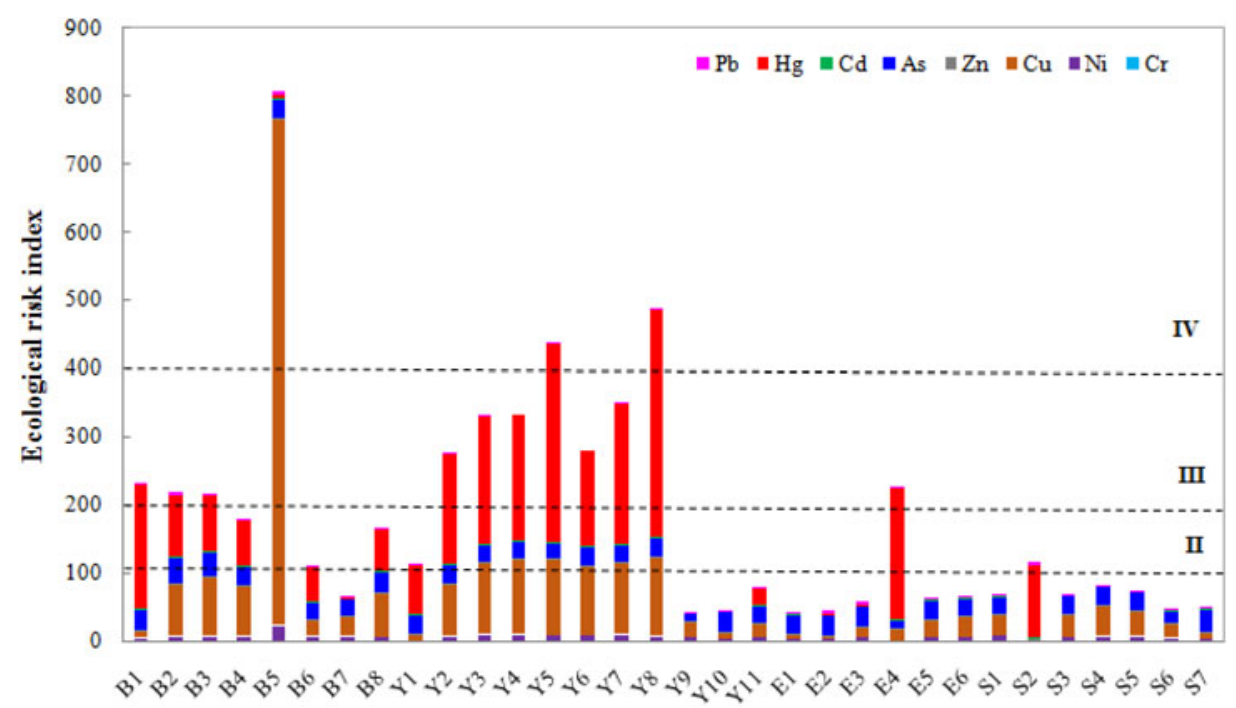

Figure 4. Potential ecological risks posed by heavy metals in coastal waters. Classes I, II, III, and IV refer to low risk, moderate risk, considerable risk, and very high risk, respectively.

used as $S_{i}$ values to evaluate the risks, more serious than those assessed by Class II standards. Ecological risk index method is usually employed to determine the potential ecological risks posed by heavy metals in soils, sediments, and dusts (Barać et al. 2016; Hakima et al. 2017; Trujillo-González et al. 2016) while its application in risk assessment on heavy metals in water especially coastal waters is limited. Therefore, this study provided new insight on ecological risks posed by heavy metals in coastal waters along Chinese coastline. Effective strategies should be proposed to control potential ecological risks of heavy metals in Chinese coastal waters. 


\section{Potential health risks of heavy metals in coastal waters}

Heavy metals in coastal waters posed potential health risks mainly through dermal contact. Therefore, health risks of heavy metals were evaluated using cancer risks and noncancer risks (Figure 5). Cancer risks were in the range of $8.71 \times 10^{-3}-8.32 \times 10^{-2}$ for adults and $3.09 \times 10^{-2}-2.96 \times 10^{-1}$ for children, respectively. Heavy metals in coastal waters of the study area exerted high cancer risks for adults at all sampling sites while they posed high and very high cancer risks for children at $50 \%$ of sampling sites, respectively. Cancer risks for children were usually several times those for adults, suggesting that children are more susceptible to hurt of heavy metals. V, Cr, As, Ni, and $\mathrm{Cu}$ were the main contributors for cancer risks, accounting for $90.98-98.60 \%$ of cancer risks.

Hazard quotients were in the range of 6.44-32.12 for adults and 22.90-114.13 for children, respectively. Hazard quotients for adults and children all exceeded the
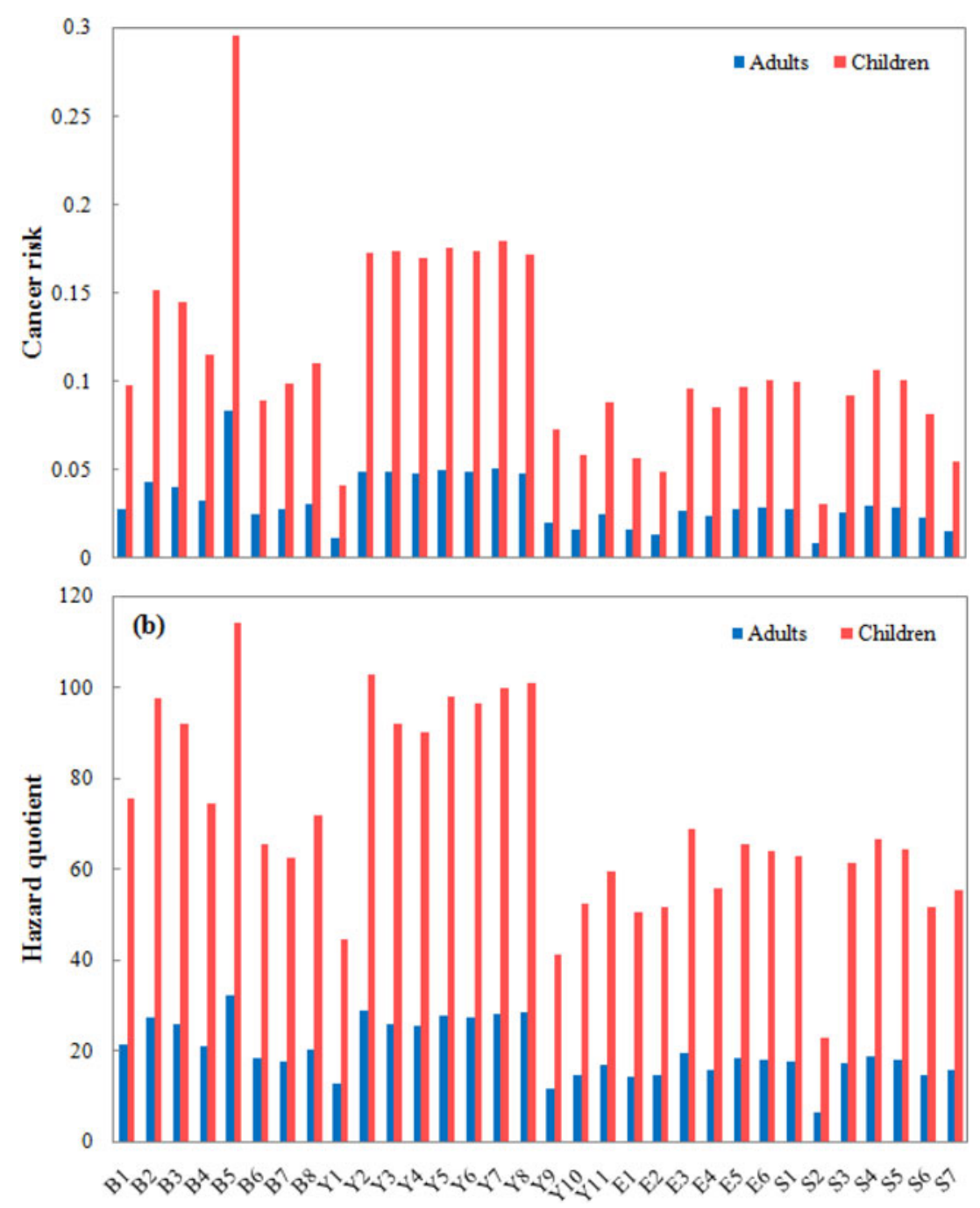

Figure 5. Cancer risks (a) and non-cancer risks (b) posed by heavy metals in coastal waters. 
unacceptable threshold of 1.0, suggesting that non-cancer risks posed by heavy metals in coastal waters were high for human beings, especially children. Elements including As, $\mathrm{Cr}, \mathrm{V}, \mathrm{Hg}$, and $\mathrm{Sb}$ were the main contributors for non-cancer risks, accounting for 93.96-98.88\% of non-cancer risks.

Heavy metals in coastal waters along coastline of China exerted high health risks for human beings. Therefore, effective control of heavy metals is necessary for regional sustainability and well-beings of residents.

\section{Conclusions}

Total 13 heavy metals were detected in coastal waters along Chinese coastline with significant spatial variations. $\mathrm{Cu}$ was the dominant heavy metal with the concentrations ranging from 6.24 to $1485.92 \mu \mathrm{g} / \mathrm{L}$. Heavy metal pollution index approach among three assessment methods obtained the worst-case evaluation results, showing that heavy pollution of heavy metals in coastal waters occurred at over $50 \%$ of sampling sites. Metals including $\mathrm{Cu}$, As, and $\mathrm{Hg}$ were the main pollution contributors. Anthropogenic sources such as industrial wastewater, sewage, traffic, and fuel combustion were the main sources of heavy metals in the coastal waters. Taking Class II levels of "Sea water quality standard of China (GB 3097-1997)" as assessment standards, approximately 46.88\%, $15.63 \%, 28.13 \%$, and $9.38 \%$ of sampling sites illustrated low, moderate, considerable, and very high ecological risks, respectively. $\mathrm{Cu}, \mathrm{Hg}$, and As also accounted for most of the ecological risks. Heavy metals in coastal waters posed high cancer risks for adults at all sampling sites while they exerted high and very high cancer risks for children at $50 \%$ and $50 \%$ sampling sites. Heavy metals posed unacceptable non-cancer risks for both adults and children. Therefore, heavy metal pollution control in the coastal regions of China is in urgent need.

\section{Acknowledgment}

The authors would like to thank the reviewers for their valuable suggestions and comments on the manuscript.

\section{Funding}

This work was supported by National Natural Science Foundation of China (41671319), Taishan Scholar Program of Shandong Province (No. tsqn201812116), One Hundred Talents Program of Chinese Academy of Sciences (Y629041021), and Two-Hundred Talents Plan of Yantai (Y739011021).

\section{References}

Agardy T and Alder J. 2005. Coastal systems. In: Ecosystems, Human Well-Being: Current State, Trends, Volume 1, Findings of the Condition, pp. 513-549. Trends Working Group of the Millennium Ecosystem Assessment Island Press, Washington, DC. http://www.millenniumassessment.org/documents/document.288.aspx.pdf 
Akhbarizadeh R, Moore F, Keshavarzi B, et al. 2016. Aliphatic and polycyclic aromatic hydrocarbons risk assessment in coastal water and sediments of Khark Island, SW Iran. Mar Pollut Bull 108:33-45. doi:10.1016/j.marpolbul.2016.05.004

Barać N, Škrivanj S, Bukumirić Z, et al. 2016. Distribution and mobility of heavy elements in floodplain agricultural soils along the Ibar River (Southern Serbia and Northern Kosovo). Chemometric investigation of pollutant sources and ecological risk assessment. Environ Sci Pollut Res 23:9000-11. doi:10.1007/s11356-016-6142-2

Carapuço MM, Taborda R, Silveira TM, et al. 2016. Coastal geoindicators: Towards the establishment of a common framework for sandy coastal environments. Earth-Sci Rev 154:183-90. doi: 10.1016/j.earscirev.2016.01.002

Cherchi A, Da Pelo S, Ibba A, et al. 2009. Benthic foraminifera response and geochemical characterization of the coastal environment surrounding the polluted industrial area of Portovesme (South-Western Sardinia, Italy). Mar Pollut Bull 59:281-96. doi:10.1016/j.marpolbul.2009.09. 016

Degger N, Chiu JMY, Po BHK, et al. 2016. Heavy metal contamination along the China coastline: A comprehensive study using Artificial Mussels and native mussels. J Environ Manage 180: 238-46. doi:10.1016/j.jenvman.2016.05.008

Edet AE and Offiong OE. 2002. Evaluation of water quality pollution indices for heavy metal contamination monitoring. A study case from Akpabuyo-Odukpani area, Lower Cross River Basin (southeastern Nigeria). GeoJournal 57:295-304 doi:10.1023/B:GEJO.0000007250.92458.de

Feng H, Jiang H, Gao W, et al. 2011. Metal contamination in sediments of the western Bohai Bay and adjacent estuaries, China. J Environ Manage 92:1185-97. doi:10.1016/j.jenvman.2010. 11.020

Ge J, Woodward LA, Li QX, et al. 2013. Composition, distribution and risk assessment of organochlorine pesticides in soils from the Midway Atoll, North Pacific Ocean. Sci Total Environ 452-453:421-6. doi:10.1016/j.scitotenv.2013.03.015

Hakanson L. 1980. An ecological risk index for aquatic pollution control, a sedimentological approach. Water Res 14:975-1001 doi:10.1016/0043-1354(80)90143-8

Hakima Z, Mohamed M, Aziza M, et al. 2017. Environmental and ecological risk of heavy metals in the marine sediment from Dakhla Bay, Morocco. Environ Sci Pollut Res 24:7970-81. doi:10. 1007/s11356-017-8367-0

IRIS (Integrated Risk Information System by United States Environmental Protection Agency). 2018. https://cfpub.epa.gov/ncea/iris/search/index.cfm?first_letter=C (accessed September 16, 2018)

Jonathan MP, Muñoz-Sevilla NP, Góngora-Gómez AM, et al. 2017. Bioaccumulation of trace metals in farmed pacific oysters Crassostrea gigas from SW Gulf of California coast, Mexico. Chemosphere 187:311-9. doi:10.1016/j.chemosphere.2017.08.098

Kim S, Lee S, Kim C, et al. 2014. In vitro and in vivo toxicities of sediment and surface water in an area near a major steel industry of Korea: Endocrine disruption, reproduction, or survival effects combined with instrumental analysis. Sci Total Environ 470-471:1509-16. doi:10.1016/j. scitotenv.2013.08.010

Lewison RL, Rudd MA, Al-Hayek W, et al. 2016. How the DPSIR framework can be used for structuring problems and facilitating empirical research in coastal systems. Environ Sci Policy 56:110-9. doi:10.1016/j.envsci.2015.11.001

Liu S, Zhang Y, Bi S, et al. 2015. Heavy metals distribution and environmental quality assessment for sediments off the southern coast of the Shandong Peninsula, China. Mar Pollut Bull 100: 483-8. doi:10.1016/j.marpolbul.2015.09.028

Meng W, Hu B, He M, et al. 2017. Temporal-spatial variations and driving factors analysis of coastal reclamation in China. Estuar Coast Shelf S 191:39-49. doi:10.1016/j.ecss.2017.04.008

Oves M, Khan MS, Zaidi A, et al. 2012. Soil contamination, nutritive value, and human health risk assessment of heavy metals: An overview. In: Zaidi A, Wani PA, and Khan MS (eds), Toxicity of Heavy Metals to Legumes and Bioremediation, pp. 1-27. Springer, Wien. 
Qu L, Huang H, Xia F, et al. 2018. Risk analysis of heavy metal concentration in surface waters across the rural-urban interface of the Wen-Rui Tang River, China. Environ Pollut 237: 639-49. doi:10.1016/j.envpol.2018.02.020

Ranjbar Jafarabadi A, Riyahi Bakhtiyari A, Toosi AS, et al. 2017. Spatial distribution, ecological and health risk assessment of heavy metals in marine surface sediments and coastal seawaters of fringing coral reefs of the Persian Gulf, Iran. Chemosphere 185:1090-111. doi:10.1016/j.chemosphere.2017.07.110

Sarria-Villa R, Ocampo-Duque W, Páez M, et al. 2016. Presence of PAHs in water and sediments of the Colombian Cauca River during heavy rain episodes, and implications for risk assessment. Sci Total Environ 540:455-65. doi:10.1016/j.scitotenv.2015.07.020

Sharifi Z, Hossaini SMT, and Renella G. 2016. Risk assessment for sediment and stream water polluted by heavy metals released by a municipal solid waste composting plant. J Geochem Explor 169:202-10 doi:10.1016/j.gexplo.2016.08.001

Takata H, Aono T, Tagami K, et al. 2012. Influence of dissolved organic matter on particle-water interactions of $\mathrm{Co}, \mathrm{Cu}$ and $\mathrm{Cd}$ under estuarine conditions. Estuar Coast Shelf S 111:75-83. doi: 10.1016/j.ecss.2012.06.014

Toro PPV, Bedoya LFV, Correa ID, et al. 2016. Impact of terrestrial mining and intensive agriculture in pollution of estuarine surface sediments: Spatial distribution of trace metals in the Gulf of Urabá, Colombia. Mar Pollut Bull 111:311-20. doi:10.1016/j.marpolbul.2016.06.093

Trujillo-González JM, Torres-Mora MA, Keesstra S, et al. 2016. Heavy metal accumulation related to population density in road dust samples taken from urban sites under different land uses. Sci Total Environ 553:636-42. doi:10.1016/j.scitotenv.2016.02.101

Tueros I, Rodríguez JG, Borja A, et al. 2008. Dissolved metal background levels in marine waters, for the assessment of the physico-chemical status, within the European Water Framework Directive. Sci Total Environ 407:40-52. doi:10.1016/j.scitotenv.2008.08.026

USEPA (U.S. Environmental Protection Agency). 2004. Risk Assessment Guidance for Superfund Volume I: Human Health Evaluation Manual (Part E, Supplemental Guidance for Dermal Risk Assessment). Office of Superfund Remediation and Technology Innovation, Washington, DC.

USEPA (U.S. Environmental Protection Agency). 2014. EPA Positive Matrix Factorization (PMF) 5.0 Fundamentals and User Guide. EPA/600/R-14/108

USEPA (U.S. Environmental Protection Agency). 2016. Regional Screening Levels (RSLs) - User's Guide. https://www.epa.gov/risk/regional-screening-levels-rsls-users-guide-may-2016

$\mathrm{Vu}$ CT, Lin C, Shern C-C, et al. 2017. Contamination, ecological risk and source apportionment of heavy metals in sediments and water of a contaminated river in Taiwan. Ecol Indic 82: 32-42. doi:10.1016/j.ecolind.2017.06.008

Wang S-L, Xu X-R, Sun Y-X, et al. 2013. Heavy metal pollution in coastal areas of South China: A review. Mar Pollut Bull 76:7-15. doi:10.1016/j.marpolbul.2013.08.025

$\mathrm{Xu} \mathrm{L}$, Wang T, Wang J, et al. 2017. Occurrence, speciation and transportation of heavy metals in 9 coastal rivers from watershed of Laizhou Bay, China. Chemosphere 173:61-8. doi:10.1016/j. chemosphere.2017.01.046

Zhang Y, Chu C, Li T, et al. 2017. A water quality management strategy for regionally protected water through health risk assessment and spatial distribution of heavy metal pollution in 3 marine reserves. Sci Total Environ 599-600:721-31. doi:10.1016/j.scitotenv.2017.04.232 